\title{
Pieles Rojas en la fiesta de La Tirana: El baile de Aniceto Palza ${ }^{1}$
}

\section{Redskins at La Tirana Festivity: The Aniceto Palza Dance}

\author{
Bernardo Guerrero Jiménez ${ }^{2}$
}

\author{
Tapado en plumas... Todo por ti virgencita... Te amo \\ Esteban Orlando de Jesús Herrera Flores, del baile chuncho \\ Tomado de su muro de Facebook, ańo 2002
}

\begin{abstract}
Resumen
En el presente artículo se analiza el origen y desarrollo de una cofradía religiosa, la de los pieles rojas, que aparece en la fiesta de La Tirana el año 1938. Se interpreta, a partir de diversas categorías tales como adaptación, traducción y apropiación, acerca del porqué de la inclusión de los pieles rojas en una fiesta religiosa y popular emplazada en el desierto de Atacama. Se afirma además que la presencia del baile "chuncho", fue un paso previo para la constitución de este baile de indios norteamericanos. Hacemos hincapié en la personalidad creativa de su fundador, Aniceto Palza Pizarro, que pone en escena un nuevo baile religioso, generando en esa época un quiebre que en la actualidad se percibe como parte del desarrollo habitual de esta manifestación religiosa del Norte Grande de Chile.
\end{abstract}

Palabras claves: religiosidad popular, apropiación, La Tirana.

\begin{abstract}
At the present article the origin and development of a religious association that is introduced in La Tirana festivity in 1938 called "pieles rojas" is analyzed. It is interpreted based upon varied categories such as adaptation, translation and appropriation. Also it includes the reason why the Redskins have been included in a religious and popular festivity settled at Atacama desert. It is stated that the presence of the dancing group "chuncho" can be regarded as a previous step to the formation of this north american dancing group. We emphasize in the creative personality of the funder: Aniceto Palza Pizarro. He organizes a new religious dancing group causing, at that time, a breakdown that to present it is perceived as part of the regular development of this religious manifestation of Northern Chile.
\end{abstract}

Keywords: popular religiousity, appropriation, La Tirana.

Recibido: 21 marzo 2016. Aceptado: 6 noviembre 2016.

1 Trabajo escrito en el marco del proyecto Dinámicas identitarias en el Norte Grande de Chile: Nación, región y religiosidad popular. FONDECYT 1141306.

2 Sociólogo. Director Instituto de Estudios Andinos Isluga. Profesor de la Facultad de Ciencias Humanas. Universidad Arturo Prat. CHILE. Email: bernardo.guerrero@unap.cl 


\section{Introducción}

Hasta los ańos treinta del siglo veinte -y usamos esta data solo como referencia-, los bailes se inspiraron en el paisaje local, particularmente en el paisaje andino. Desde esa época en adelante, hay dos referencias interesantes relacionadas con la aparición de los bailes de indios del oeste norteamericano, en especial de pieles rojas. La más temprana información es la del baile de Daniel Mercado, del que se fija su nacimiento el año 1931. Pero hay dudas respecto a ese dato. Es probable, y así lo dice Arturo Barahona, que ese baile originalmente chuncho, haya sido formado en esa fecha. Como veremos más adelante, hay una transición de chuncho a pieles rojas que explicaría el origen en esa fecha. Hay consenso entre los dos más antiguos caporales vivos, Arturo Barahona y Héctor Rodríguez, de que Palza fue el creador de este tipo de baile. Lo mismo afirma la actual caporal del baile de Damián Mercado, Vicenta Dávila.

El baile chuncho de inspiración amazónica, compuesto por hombres y mujeres, cubiertos por plumas, es uno de los bailes más tradicionales de la fiesta de La Tirana, a pesar de que su estandarte mencione como fecha de formalización el año 1923. Es un baile que usa la percusión y lacas, al ritmo del trote (Campos, 2009). Mientras que los pieles rojas de inspiración en los indios norteamericanos aparecen a fines de la década de los treinta, usan preferentemente percusión y pífano (pito) para marcar el ritmo dos por tres (Méndez, 2016).

En Iquique, Margot Loyola ${ }^{3}$ le preguntó al sastre Aniceto Palza Pizarro ${ }^{4}$ acerca de las razones que tuvo para elegir las vestimentas de los pieles rojas en el

3 Margot Loyola (15 de septiembre de 1918 - 3 de agosto de 2015) investigó y difundió el folclor chileno hasta el día de su muerte. Sus publicaciones incluyen los libros Bailes de tierra (1980), El cachimbo (1994) y La tonada. Testimonios para el futuro (2006); además de los videos Danzas tradicionales de Chile (1994), La zamacueca (1999) y Los del Estribo, cantos y danzas populares de Chile (2001).

4 Palza nace en Pisagua el 4 de junio de 1907 y muere en Iquique el 22 de noviembre de 1972. Está enterrado en el cementerio de La Tirana, en el mausoleo de la familia Farías. Margot Loyola le puso una placa de bronce con el siguiente texto: "Al recuerdo de Aniceto Palza. Forjador de Bailes Pieles Rojas. Al amigo incomparable. Al maestro generoso". Margot Loyola. La Tirana. Julio de 1980. baile que estaba formando. La respuesta no se hizo esperar: "Porque era bonita, porque era distinta y me gustaba”. Esta frase encierra muchos sentidos. Y lo tiene en la medida en que aceptamos como cierto el sentido de la afirmación. Palza se vio en la coyuntura de tener que armar un baile y dotarlo, como bien se sabe, de una identidad. Y ésta la encontró en la performance de los pieles rojas. Lo que hizo este peregrino, y han hecho la mayoría de los sujetos como él, es apropiarse de una oferta performática que estaba a su disposición. El sentido común, no solo aquél que es definido por la ciencia como de segundo orden o espontáneo, sino también el socioantropológico, han remitido el acto de Palza a una copia de las imágenes transmitidas por el cine de la época. Es la tesis de Uribe (1973) que otros reproducen (Mercado, 2014). Pretendemos en este artículo poner en discusión esa afirmación.

Fundar un baile religioso es un acontecimiento que rompe la monotonía de la vida corriente de la gente, toda vez que se inscribe en una práctica cotidiana de los habitantes del Norte Grande, en tanto el baile y el canto forman parte del paisaje sonoro de este territorio. Y no es un fundar cualquiera. Es un fundar con la pretensión de la permanencia y trascendencia en el tiempo. Palza y muchos otros como él son creadores de una institucionalidad en la que la acción religiosa es el centro de toda esa estructura. Fundar bailes religiosos supone, entre otras consideraciones, definir la identidad de lo que se está proyectando. Elegir un nombre, elegir los colores de sus atuendos y, enseguida, dotarlo de una presencia vital que no solo se manifiesta cada 16 de julio, sino que a través de todo el año, en actividades ordinarias como juntar dinero, pero siempre bajo la presencia de la imagen de la Virgen o del santo.

La clásica distinción entre lo sagrado y lo profano establecida por la sociología occidental, sobre todo por Durkheim (1982), no aparece tan nítida, es una dicotomía que en el Norte Grande no resulta evidente. La sede social del baile o la casa del dueño del mismo están llenas de esa presencia fuerte, atractiva e inhibidora que ejerce la Virgen o el santo sobre los peregrinos.

La fundación de un baile religioso posee la marca de la presencia de lo sagrado. La fundación conlleva el compromiso, la manda, que supone un contrato 
tácito pero eficaz entre el creyente y la Virgen. Aniceto Palza, el sastre, reproduce lo que tiene a mano: decenas de bailes religiosos que concurren a la fiesta de La Tirana. Pero debe diferenciarse de los demás.

Las páginas que siguen pretenden contextualizar y discutir el gesto creativo del sastre. Y en su persona, a todos los que como él han realizado este tipo de actos. Todo ello por cierto en el marco de la construcción de la nación, mediante el proceso de chilenización y por la actividad del salitre tanto en la pampa como en los puertos, que aunque estaba en crisis, no dejaba de ser la más importante.

\section{Breve bosquejo histórico}

El pueblo de La Tirana, al igual que los otros del Norte Grande de Chile, se fue haciendo a medida que las demandas económicas lo requerían. La ocupación y diseńo urbanístico nunca fueron ordenados de forma racional. Así como en la mayoría de las ciudades del Norte Grande de Chile, no hubo en La Tirana una élite ilustrada que pensara cómo humanizar ese espacio. Los datos que tenemos de este poblado indican que en el siglo XVIII ya se habían asentado algunas familias (Núñez 1989, p. 28). Se afirma que este pueblo fue fundado en 1567. Sin embargo García, sin entregar argumentos, lo fecha en 1765 (García, 2009, p. 24).

La Tirana siempre se estructuró en torno a las tareas mineras. Primero como surtidora de agua, luego por la presencia de tamarugos para la leńa y después para la crianza de ganado.

Al parecer, y siguiendo a Núńez (1989, p. 28), el poblamiento de La Tirana tiene sus inicios en el año de 1780. Es en el siglo XVIII que la pampa del Tamarugal empieza a habitarse, siguiendo el patrón rural andino. La economía se sustentaba en la crianza de animales, en la elaboración de carbón de leña y en el procesamiento de la plata.

Para Núnez, el origen del culto a la Virgen del Carmen hay que buscarlo a fines del siglo XVIII, período en el cual se detecta la aparición de topónimos ligados a la Virgen. A lo largo del siglo XVIII, prosigue Núñez,
[...] se desarrolló una población minera bajo condiciones de explotación bastantes deplorables. Todos habían recibido una intensa formación católica puesto que en su mayoría provenían de valles y oasis donde los señores españoles, junto a sus magníficas iglesias, habían impuesto una rigurosa catequesis. Tanto los mineros de Huantajaya como los buitroneros del Tamarugal eran profunda e intensamente devotos (1989, p. 32).

Hasta la crisis del salitre en los años cincuenta, con el cierre de la oficina salitrera Humberstone, la actividad económica del pueblo de La Tirana giró en torno a la extracción del salitre. La fiesta del 16 de julio lo visibilizaba, por lo menos, una semana al año. La vida cotidiana de sus habitantes oscilaba entre la crianza de animales: cabras, corderos, ovejas y el comercio. Tres bailes religiosos, todos de pastorcitos, se daban cita cada 6 de enero para Pascua de Negros. Al decir de Luis Choque, "ésa es nuestra fiesta, no el 16 de julio" (Entrevista, 11 octubre 2014). Desde los ańos cincuenta, grupos organizados de pobladores interpelan a Iquique por mejoras. Mejores caminos, luz eléctrica, alcantarillado, entre otras. Los tiraneños hacen sentir el peso del centralismo que sobre ellos se ejerce desde Iquique. El dirigente Andrés Farías Gamelis (1925-2009) es el encargado de movilizar esas demandas. La expresión de la crisis y conflicto entre la gente de La Tirana y las autoridades de Iquique se manifestó el ańo 1970 con la construcción de un quiosco en la explanada del pueblo, frente a la iglesia (Guerrero, 2014). Desde el año 1971, dependen de la comuna de Pozo Almonte, y el año 2012, los pobladores lucharon por pertenecer a la comuna de Pica.

Con la explotación del salitre desde fines del siglo XIX, esta fiesta alcanzó una dimensión más regional. El proletariado salitrero, comerciantes, entre otros, organizados en bailes religiosos, se dotaron de una organización, quizás inspirada en la del movimiento obrero, para organizar el culto y defenderse de los ataques de la llamada "opinión pública". Hasta los años setenta, los bailes organizados en asociaciones y federaciones lograron una gran autonomía respecto de la jerarquía de la Iglesia católica y de otras organizaciones tales como los partidos 
políticos (Van Kessel, 1987). Con el golpe de Estado de 1973, la situación cambia y los bailes religiosos son objeto de sospecha para las nuevas autoridades. Se produce aquí un proceso de acercamiento a la Iglesia católica. Esta institución religiosa, durante la dictadura militar chilena, defiende los derechos humanos y en tal condición, les ofrece protección a los bailes religiosos. Empieza aquí un nuevo proceso, marcado ahora por la evangelización de los bailes religiosos (Tennekes y Koster, 1986). Esto se advierte, por ejemplo, en el cambio en los cantos religiosos: el canto tradicional decía: "Campos naturales déjanos/ pasar porque tus devotos/ vienen a adorar". Hoy es "Campos naturales déjanos/ pasar porque tus devotos/ vienen a cantar". El cambio es notable. A la Virgen o al santo, no se le adora; a Dios, sí.

\section{La fiesta de La Tirana}

Esta fiesta es como un gran texto que no tiene un solo autor. $\mathrm{Y}$ en muchos de los casos, sus autores entran a veces en contradicción. Sus gramáticas y semánticas dependerán mucho de quién las enuncie. La leyenda que la crea ha sido también objeto de discusiones, aunque nadie niega su eficacia y el hecho de que la Nusta se haya convertido al cristianismo, y por ello, haya sido sacrificada por sus hermanos, los indios.

A la variedad de autores de la fiesta de La Tirana le corresponde también una variedad de lectores. Hasta los años cincuenta, la fiesta de La Tirana se presentaba como un todo homogéneo. Los bailes religiosos que asistían presentaban un denominador común. Eran cofradías locales que representaban, en parte, lo que el paisaje geográfico y económico les suministraba, lo cual las relacionaba con la economía agrícola y pastoril del territorio. Entre estas cofradías encontramos a las Cuyacas, Chunchos y Morenos, entre otros. Los Chinos venidos de Andacollo, con su indumentaria de mineros, pronto sintonizaron con el ambiente festivo (Guerrero 2007). Era una fiesta local que no traspasaba las fronteras regionales, a excepción de los Chinos. ${ }^{5} \mathrm{El}$ aparato

5 García entrega interesantes datos de los nombres de las cofradías que asisten a La Tirana a comienzos del siglo XX. Esta información la toma de la prensa entre 1885 al 1933. En el año 1907 hay bailes con nombres regionales, eclesiástico tenía una mínima injerencia. Por ejemplo, el año 1900, el obispo de la época, Juan Guillermo Carter Gallo, acude solamente por el día 16 de julio. Hoy la situación es diametralmente opuesta. La Iglesia católica se desplaza en forma masiva a la fiesta. Y permanece en el pueblo por cerca de 15 días.

Hasta los años sesenta, las relaciones entre bailes religiosos e Iglesia eran de conflicto. Esta última, a menudo tildaba la fiesta de pagana. El testimonio de los viejos bailarines así lo demuestra. Don Nelson Jeria, el último caporal del baile Marinero de Santa Laura, nos dice que al terminar la fiesta, cantaban por el pueblo, en ritmo de cacharpaya: "Adiós chascones de La Tirana", "Adiós comerciantes especuladores ya se han hinchado como alfajores". O "El cura de este año no quiere velas, quiere que los bailes le traigan plata” (Entrevista a Nelson Jeria, enero 2015).

Los peregrinos, obreros mestizos, excampesinos, atraídos por la riqueza del salitre, fueron los principales protagonistas de esta festividad. Los pastores y campesinos andinos, a través de su economía otorgaban los recursos, como alfalfa y leña, entre otros, para la economía del salitre en expansión. Toda vez que acompańaban a los bailes en sus mudanzas, mediante la ejecución de los instrumentos de vientos, aerófanos en su mayoría. El documental de Pablo Garrido del año 1944, el primero de ese estilo, así lo demuestra.

La autonomía de esta fiesta, en tanto era administraba por los propios bailes religiosos, no estaba exenta de conflictos con la Iglesia católica. La disputa por el uso del templo parece ser la principal razón de estos roces. Su punto más alto es la acción protagonizada por "el fundador y caporal del baile piel roja, Aniceto Palza, que agrede a un cura, ya que éste no le abre las puertas de la iglesia" (Entrevista a Arturo Barahona, octubre 2013). Comenta que el cura había dicho que en vez de poner velas a la Virgen, debían dejarle monedas. La reacción de Palza fue la de darle una bofetada (Entrevista a Héctor Rodríguez, 27 septiembre 2014).

como Morenos, Coyahuayos, Gameros y Gambas (García, 2009, pp. 45-47). 
Los peregrinos que asisten a la fiesta de La Tirana, a través de los bailes religiosos van a desarrollar una práctica creativa que se expresa en mudanzas, cantos y ornamentaciones de la imagen de la Virgen que cada baile posee. Por inventiva sociocultural entendemos "la resolución creativa de los problemas por parte de una inteligencia que experimenta" (Joas 1998, p. 282). Se trata de una capacidad para modelar lo que viene de "afuera" e insertarlo en una práctica situada social e históricamente.

Por puertos y la pampa del Norte Grande de Chile, gracias a la explotación del salitre, circularon bienes culturales como zarzuelas, óperas, obras de teatro, además de impresos de todo tipo, como periódicos fundamentalmente. En los llamados impresos se destacaron revistas que bajo el nombre de "historietas" satisfacían la necesidad de llenar el tiempo libre, a través de la combinación de textos y gráficas. Una de éstas fue la revista de diez centavos Dime Novel, que narraba aventuras de todo tipo, y en especial de la colonización de los indios norteamericanos.

\section{Breve discusión teórica}

Para descartar el concepto de imitación o de copia, preferimos usar el de apropiación ya que implica un acto por parte de los actores de hacer suya una imagen, en este caso, un conjunto de mudanzas, con música y cantos. Este concepto en su expresión más precisa:

La noción de apropiación conlleva dos ideas dominantes. Por un lado, la adaptación de alguna cosa a un uso definido o a una destinación precisa; de otro lado, la acción dirigida a entregar en propiedad alguna cosa. Intervención humana más propiedad material o simbólica, donde la forma de marcar un territorio (disposiciones de objetos y de signos) es la manera de representar el espacio habitado (Serfaty-Garzon, 2003, p. 2).

Varias ideas son relevantes de establecer aquí. El desplazamiento de un territorio a otro de una práctica cultural nacida localmente, y reutilizada, en este caso, en el Norte Grande por grupos de obreros, hombres y mujeres, que la redirigen a la Virgen del Carmen. Se conjuga lo material y lo simbólico en tanto se transfieren de un lugar a otro, prácticas religiosas y culturales. Una forma de representar otra identidad, aquí del piel roja o de otros grupos de indios norteamericanos como sioux, cheyennes, dakotas, castores, etc.

Se apropian de sus vestimentas, mudanzas y sonidos, pero sus cantos se dirigen a la Virgen del Carmen, y sus letras hablan de la geografía local: el desierto de Tarapacá; señalan el nombre del lugar de donde vienen, hablan de la naturaleza del Norte Grande, etcétera. Pero también existe por parte de quienes se apropian de esos bienes, un vínculo emocional por esas formas culturales "exóticas". Arturo Barahona González (1929), el más antiguo de los caporales piel roja, siente una profunda admiración por los indígenas del oeste norteamericano. En su casa tiene varios libros sobre el tema. Tanto en La Tirana como en Iquique, con su traje, actúa como un "indio de verdad”. Sin duda que a él las revistas y luego el cine, lo marcaron profundamente.

Hay además un gesto de transformar lo extraño en algo conocido. Una estrategia para hacer más familiar al piel roja en el Norte Grande. Así se plantea en el concepto de traducción usado por Innerarity:

Bajo esta expresión debe entenderse todo aquello que -desde los traductores, los ritos comunes, zona de contacto, cooperación y competición- sirven como técnicas para la comprensión, normalizan la extrańeza transformándola en una alteridad que pueda constituirse en interlocutor tanto en términos de cooperación como de rivalidad (Innerarity, 2008, p. 209).

De este modo, Damián Mercado y Aniceto Palza hacen cercanos a esos indígenas lejanos y de paso, vía la traducción, los inserta en la realidad local. Él, además, siente con el indio piel roja, sobre todo con el jefe, una simbiosis absoluta. La gente así lo recuerda: "Parecía un indio de verdad" (Entrevista a Luis Choque, 11 octubre 2015, pueblo de La Tirana).

Latour por su parte nos entrega una interesante distinción entre intermediario y mediador, que para los 
fines que nos ocupan, puede ser relevante. El intermediario es el que transporta significado o fuerzas sin transformación. Basta definir sus datos de entrada para obtener los de salida. Un computador, dice este autor, es lo que más se parece a un intermediario. Mientras que el mediador interviene en el proceso, los modifica y los altera. Cito a Latour: "Los mediadores transforman, traducen, distorsionan y modifican el significado o los elementos que se supone deben transportar" (Latour, 2005, p. 63). Desde esta perspectiva, los actores sociales que se dieron a la tarea de crear en forma personal o colectiva los bailes religiosos actuaron más como mediadores que como intermediarios.

\section{Hipótesis de interpretación}

El paso de chuncho a piel roja, producto de una reinterpretación y resignificación simbólica, no se puede entender sin la presencia del baile de Damián Mercado, pieles rojos, que se ubica en el medio de ambas cofradías. No es chuncho ni tampoco piel roja. Éste es el eje de nuestra discusión.

En el Norte Grande y desde fines del siglo XIX, según anotan las informaciones de la prensa, aparecen bailes de indios vestidos con plumas y bailando con instrumentos de percusión y de viento. Uno de ellos, que permanece hasta la actualidad, es el baile chuncho, que representa al habitante de la selva y que expresa ese territorio, de una u otra manera, a través de su indumentaria colorida: plumas y chontas (especie de lanza). El año 1923 aparece fechada la fundación de este baile, por lo que es dable suponer que el acto creativo de Aniceto Palza, al fundar su baile, haya sido la sumatoria de todo lo anterior: lectura de esos impresos y la presencia de bailes ataviados con plumas y lanzas.

La aparición del biógrafo, en el Norte Grande, no ha sido fechada. Los datos que existen son de los años cincuenta, y se carece de documentación para analizar el tipo de películas exhibidas. Solo a partir de esa década se observa un boom de películas de "indios" y de su exhibición en los cines de los puertos y en las oficinas salitreras. Para reafirmar lo anterior cito a Uribe:
El iquiqueño Manuel (Damián) Mercado, caporal de un baile chuncho, organizó este baile, en $1930 \ldots$ algo más tarde, Aniceto Palza, sastre de bailes, se separó de Mercado y reformó la coreografía y el atuendo de los primeros pieles rojas, formando un nuevo conjunto... El baile de pieles rojas es mixto, acrobático y, al mismo tiempo, ceremonioso. Ellos y ellas bailan con lanzas y hachas de chonta y cuchillón de madera. En sus saltos y vueltas se parecen a los chunchos, de los que han derivado. Hay también un baile de indios apaches, que llevan una sola pluma sobre la cabeza y visten, convencionalmente, como los indios americanos de esa tribu. Blanden puñales y lanzas de chonta. En los giros de la danza se asemejan a los pieles rojas (Uribe, 1973, p. 91).

Méndez en su tesis sobre los bailes piel roja, afirma de modo complementario a lo que planteamos:

Mucho hace suponer que la adaptación significante de los filmes, fue motivo de inspiración y a la vez, una forma de representar un nuevo paradigma social que fue consciente y eficaz para darle uso en cada nueva fiesta. Esto representa un primer nivel identitario en el proceso de conformación hacia derivas de posteriores bailes de indios que, poco a poco, comienzan a poblar el norte de Chile y sus fiestas religiosas, todo esto sin estar exentos de cuestionamientos en su proceso, por la adopción de etnias foráneas (Méndez 2016, p. 42).

Este autor discute acerca de la influencia del cine en la conformación de estos bailes, pero también se pregunta acerca de la accesibilidad que los obreros pampinos tuvieron a estos bienes culturales. Los biógrafos y las bibliotecas no eran lugares comunes en esta parte del país. ${ }^{6}$

6 La tesis de doctorado de Prado (2012) no consigna la fecha en que aparecen los primeros biógrafos en el Norte Grande, menos aún de su programación. Lo mismo en Vera-Pinto (2016). Bravo Elizondo entrega un listado de algunos de ellos, pero sin fecha de inauguración (1986, p. 131). 
La prensa local, en especial El Tarapacá, la única fuente documental escrita que se refiere a La Tirana, ve esta manifestación como residuo del pasado, algo que con el tiempo debe desaparecer. Engloba además bajo la categoría de chunchos todos los bailes religiosos:

Las pintorescas comparsas de bailarines, o para ser más exactos de bailadores, que tuvieron a su cargo el "Clou" del programa, sumaban un total de mas de 600 integrantes, disciplinados en alrededor de 20 conjuntos con sus respectivos jefes, y caporales.

La abigarrada variedad de los disfraces, perceptiblemente trabajados con una dedicación estupefactante, las máscaras estrambóticas, la música, el ritmo y el baile. Extrañamente evocadores de la expresión exterior, elemental e instintiva del sentimiento religioso que tienen otros pueblos, todos constituían un conjunto inusitado para el espectador que por primera vez hubiese asistido a presenciar estos actos.

El giro peculiarísimo que toman las fiestas, su poder de atracción sobre la masa popular y las reacciones que en ello provoca, las oscuras y curiosas tradiciones que se descubren entre los participantes, a titulo inmemorial, el aguafuerte, por así decirlo, que forma el pequeño e improvisado comercio de medallitas, escapularios, baratijas, fruta, limonada, comida, etc. El crudo colorido pictórico que imprime a toda la agitada escena la refracción violenta de un sol vertical sobre los más absurdos colores, serían dignos de ser interpretados en toda su riqueza por alguna pluma o pincel, de verdadero valor, que tendrá en este "pandemónium" una copiosa cantera de humanidad estruendosa y elemental.

Hermosa fiesta sin duda, dándose naturalmente a la palabra, una significación condicional. Desde luego extraordinariamente típica y por desgracia desconocida en absoluto en el resto del país. Sin duda la serie de actos a que da origen la festividad de La Ti- rana constituye un conjunto de costumbres, tal vez de las mas interesantes que hayan en Chile (El Tarapacá, 17 julio 1937, p. 4).

Las fiestas del año 1938, 1939 y la de 1940, años en que aparece el baile de Palza, no son consignadas de ningún modo. Como se dijo más arriba, la etiqueta de chunchos no deja ver otros bailes.

\section{El cine y su influencia en el Norte Grande}

Los estudios de Van Kessel sobre la fiesta de La Tirana han insistido en el carácter emancipatorio del movimiento de peregrinos (1987). No se trata de un movimiento que levanta sus fronteras para protegerse de las influencias externas. Al contrario, y siguiendo el análisis del sociólogo holandés, esta población mestiza ha demandado al Estado, sobre todo en los ańos sesenta, mayor integración no solo económica, sino que también en los aspectos educativos y políticos.

Interesa ahora reflexionar acerca de cómo este movimiento abierto por naturaleza asimila y transforma los elementos que provienen de otras culturas. Es el caso de, por ejemplo, el cine de wéstern, que en los años cuarenta se convierte en la industria cultural de mayor penetración en América Latina (Fernández, 2009). Nos referimos aquí al uso de trajes y a la ejecución de danzas, entre otros aspectos.

La industria del cine, y sobre todo el género del wéstern, tiene una presencia relevante en el Norte Grande de Chile. Los temas tradicionales de este género, fundamentalmente en lo que dice relación con la conquista del oeste y la construcción cultural que el blanco produce respecto del indio, serán objeto de consumo por parte de los obreros salitreros.

Llama la atención al observador encontrar a los bailarines del Norte Grande de Chile vestidos con los atuendos de los nativos norteamericanos. ¿Qué hace un indio norteamericano en el desierto de Atacama? ¿Qué hace un cheyenne o un sioux en la fiesta de La Tirana?

La respuesta a esta pregunta pasa por recordar lo que hemos ya anotado: la influencia del cine norteamericano. Sin embargo caben aquí varias acotaciones. 
Una de ellas tiene que ver con que si realmente la influencia del wéstern se masificó en el Norte Grande de forma tal que los peregrinos vieran en él una forma de apropiarse de lo que se exhibía. Creemos que no. No es dable sostener que en todas las oficinas salitreras se viera cine, tal como se piensa. No todas tenían instalaciones para proyectar filmes. Investigadores como Pedro Bravo Elizondo (Entrevista, octubre de 2007) afirman la existencia de individuos que de paso por las oficinas, proyectaban películas. Sostiene además la difusión, y esto es más probable como medio de influencia, de las historietas llamadas Dime Novel, conocida como novela de diez centavos. Historietas gráficas que ilustraban aventuras. Datan del siglo XIX, eran sensacionalistas y tenían como fin la entretención. Fueron protagonizadas por exploradores, soldados, detectives o cazadores de indios.

En el cine, en la década del veinte con el cine mudo, ya empieza a aparecer el indio. Tal es el caso, por solo nombrar dos, de By Indian Post (1919) y de The Iron Horse (1924), ambas de John Ford, donde el piel roja aparece como flojo, ladrón, vengativo.? Pero no aparecen indígenas danzando alrededor de una hoguera, con sus atuendos rituales: pintados y cantando. No existe una oferta visual y menos sonora de esas danzas que permitan su apropiación por parte de los peregrinos. Podemos pensar que tal vez los circos en sus presentaciones hayan mostrado alguna pieza con indios, tal como lo hacía Buffalo Bill. De los circos solo sabemos de uno que estuvo en la plaza Montt el 21 de diciembre de 1907, fecha

7 Las novelas de James Fenimore Cooper (1789-1851) son consideras como el insumo que habrían de nutrir al cine de wéstern, nacido a comienzos del siglo XX en los Estados Unidos. La más famosa El último de los mohicanos, publicada en 1826, llevada al cine en diversas épocas, la más actual la de 1992. La primera fue del año 1920 y pertenece al cine mudo. Sin embargo, el cine, por presiones del mercado, de la propia industria, ha ido en muchos de los casos tergiversando los contenidos de la obra de este autor (Fernández 2009, 227). Fenimore dio cuenta de la formación de la identidad de los Estados Unidos, a través de temas como la conquista del oeste, la relación con sus nativos y el trágico destino del piel roja. Los autores de novelas baratas como Dime Novels contribuyen a esta popularización y sobre todo a la elaboración de una imagen de los pieles rojas, en tanto salvajes, atrasados, etcétera; mostrados como obstáculos a la civilización. de la matanza obrera en la escuela Santa María, pero que al día siguiente continuó con sus presentaciones. Éstos por lo general mostraban espectáculos de boxeo, entre otros. Pero no tenemos más antecedentes de su programación.

Es en la década del cuarenta cuando se masifica la figura de este "otro", portador y representante de la "barbarie", en contraposición al hombre blanco, síntesis y promotor de la Civilización. ${ }^{8} \mathrm{Y}$ es ésta la época en que la industria del cine se masifica en el Norte Grande. ${ }^{9}$ El historiador inglés dice: "Prácticamente todos los wésterns que cualquiera de nosotros querría volver a ver son posteriores a La diligencia (que se estrenó en 1939)" (Hobsbawm, 2013, p. 300).

El cine norteamericano, en el género del wéstern, construyó al "otro", en este caso al indio, y también al mexicano, como un grupo étnico acorde con los mandatos que el discurso blanco y colonialista construyó para estos casos. Lo mismo hizo con otros grupos como los gitanos, por ejemplo. Esas imágenes no eran más que variaciones del colonialismo desarrollado en la Europa del siglo XVIII y XIX. Civilización y Barbarie, representada la primera por el blanco y el ferrocarril, y la segunda, por el indio.

8 El género wéstern encuentra su raíz iniciática en el film Asalto y Robo al Tren (The Great Train Robbery) que Edwin Porter rodara en 1903, época del cine mudo, haciendo populares a estrellas interpretativas como Broncho Billy Anderson y Williams S. Hart. Cineastas como David Wark Griffith con La Masacre (The Massacre, 1909) y una gran cantidad de cortos dieron vida al género. Durante la etapa del cine mudo John Ford plasmaría en El caballo de hierro (The Iron Horse, 1924), un estilo entre romántico y épico que sentaría la estética que caracterizará al wéstern clásico popularizado con su obra cumbre La diligencia (Stagecoach, 1939) luego de muchos años de filmar wésterns de clase B. La diligencia fue un punto de inflexión donde personajes y situaciones cobraban más peso y encontraban su densidad moral. Ese mismo año Cecil B. De Mille filmaría de forma espectacular la construcción de una vía ferroviaria en Union Pacific (1939). Los cimientos del género estaban poco a poco consolidándose y la época de esplendor no tardaría en llegar (http://www. enclavedecine.com/2010/03/historia-del-western.html. Visitado el 31.05.2016).

9 La referencia más temprana que disponemos del cine en Tarapacá, se conoce por el incendio en Caleta Buena el año 1930. Desconocemos qué pelìcula se exhibía en ese momento. El incendio comenzó en el foyer. 
Éste aparece hablando una lengua que nadie entiende y cuando lo hace en el idioma inglés, está lleno de imperfecciones.

Incluso así, el cine desde la década de los cincuenta logró presentar, aun careciendo del rigor antropológico, imágenes que servirán de inspiración para la performance de la fiesta de La Tirana. De este tremendo dispositivo comunicacional que es el cine, como lo fueron antes las revistas de caricaturas o cómics, los habitantes del Norte Grande de Chile adaptaron y recrearon variadas formas de danzarle a la Virgen.

\section{Genealogía de los bailes pieles rojas del Nor- te Grande. Los bailes de indios}

Los santuarios del Norte Grande de Chile, Ayquina en la región de Antofagasta, La Tirana y San Lorenzo en Tarapacá y Las Peñas en Arica y Parinacota, constituyen un circuito ceremonial y ritual que cubre buena parte del año litúrgico de la llamada religiosidad popular. A estos santuarios acuden, para el caso que aquí nos interesa, varias cofradías vestidas a la usanza de indios norteamericanos con sus variantes como dakotas, sioux, comanches, cheyennes, apaches, castores, etcétera. Todos ellos tienen en común apropiarse de estas tribus del oeste norteamericano. $\mathrm{Y}$ a todos se les denomina bailes de indios, para diferenciarlos de los morenos, gitanos, entre otros.

El baile de pieles rojas fue fundado por Aniceto Palza el año 1938 y es al que prestamos atención. Los otros surgen ya sea por cisma al interior de los mismos, o bien en otras ciudades como Arica, Calama, Antofagasta, por influencia de los de La Tirana. Este santuario es el gran creador y difusor de este tipo de bailes, que alcanza en la década de los ańos cincuenta su mayor desarrollo. Se crean en el Norte Grande ocho de estas cofradías.

Los bailes presentan hasta la década de los setenta una estructura organizacional más bien laxa. Se articulan, como en el caso del grupo de Aniceto Palza, en torno a un líder carismático que los congrega y organiza. Otros lo hacen alrededor de familias extendidas, lugar de residencia, etcétera. El jefe ritual, el caporal, es además el jefe político. Los cismas ocurren por desavenencias con el líder y por no contar con estructuras normativas que mitiguen o resuelvan los conflictos. Desde la década de los setenta los bailes empiezan a dotarse de estructuras más sólidas: eligen a sus directivas, y las renuevan periódicamente. En la actualidad queda poco de esos bailes. El más clásico es el baile Piel Roja del Espíritu Santo de Arturo Barahona, bailarín formado en las filas de Aniceto Palza.

En la trayectoria del baile de Mercado y Palza, el primer cisma es el que se produce por los conflictos entre ellos. Pedro Dávila nos cuenta: "Eran dos bailes, se llamaban 'Piel Roja Danzante, Daniel Mercado'. Danzante porque resulta que nosotros teníamos un traje blanco, con un gorrito. Ese baile lo llevaba una tía, que en paz descanse. Nosotros bailábamos aquí por la Pascua, con el 'niñito Dios'. Y posteriormente empezamos a ir a La Tirana. Aquí el único baile rojo que había se llamaba Palza. O sea, piel roja. Yo en ese tiempo tendría como 7 u 8 años más o menos. Entonces este caballero Daniel Mercado bailaba en ese baile, era guía, y pelearon, como en toda parte y este caballero se salió y este caballero como conocía mi tía, que tenía el baile danzante, que era donde nosotros bailábamos nosotros y habló con ella para que lo autorizara sacar un baile piel roja, igual que Palza. Este caballero se llamaba Daniel Mercado. Entonces para ir a La Tirana llevábamos los dos bailes, ella se preocupaba de su parte y él su parte, en un mismo baile. Así fue el primero, el segundo y en el tercer ańo este caballero se enfermó" (Entrevista realizada en octubre de 1990).

Reconstruir la historia y génesis de los bailes pieles rojas que asisten a las fiestas de Norte Grande es complejo. La inexistencia de documentos escritos juega en contra. Queda el recurso de la memoria y sobre todo, de la buena memoria de aquellos que aún tienen la capacidad de recordar los hechos más importantes. Advirtiendo eso sí, que el ejercicio de la memoria está condicionado por diversos factores. Ésta, ya lo sabemos, es una construcción que lee el pasado de acuerdo a ciertos requerimientos. Las relaciones entre historia y biografía sirven para dar cuenta de cómo se reinterpreta el pasado. La memoria no es objetiva ni neutral y opera en base a 
acontecimientos y no a fechas (Candau, 2001). Más aún si advertimos que muchos de lo que pueden contar esta historia han fallecido. La tradición oral funciona aquí como transmisor de historia, de testimonios hablados, que tienen que necesariamente ser narrados (Vansina, 1967, p. 33). Uno de estos sujetos capaces de recordar, es don Arturo Barahona González, nacido el año 1929. Barahona reconoce a Aniceto Palza como el fundador del primer baile, allá en el año 1937. Sin embargo no reconoce -u olvida- la obra de Damián Mercado. ${ }^{10}$ Esto se complica más cuando Margot Loyola reconoce a Aniceto Palza como el creador del baile piel roja. En una publicación sin fecha, la folclorista recrea, en una entrevista, la historia del baile. Habla con Aniceto Palza. Margot Loyola dice: "A usted ando buscando, digo a don Aniceto Palza, a quien encuentro regando su jardín en la puerta de su casa, en la Población O’Higgins de Iquique. Su mirada penetrante mira fijamente a mis ojos y su mano estrecha la mía. Y empezamos a conversar; mientras lo escucho no puedo dejar de sentirme atraída por sus manos, de ademanes enérgicos, que me invitan a pasar a su casa. Don Aniceto fue el creador del baile Pieles Rojas en el año 1932, según sus noticias".

Tanto Barahona como Loyola coinciden en reconocer a Palza como el gestor de este importante baile. Ambos ignoran la figura de Damián Mercado. ${ }^{11}$ Sobre este último, poco o nada se sabe. Sin embargo, el letrero de la sede en La Tirana es claro.

Lo anteriormente expresado tanto por Palza, Barahona y Loyola, más la foto de la sede social y la inscripción del estandarte del baile de Damián Mercado, permiten afirmar que tanto Palza como Mercado son los fundadores de estos bailes. Díaz habla de la separación entre Palza y Mercado, pero no entrega mayores antecedentes (2003).

Carlos Lavín ofrece esta información de interés sobre la fiesta de La Tirana y señala la existencia de un canto, el "quele, quele", que aún se interpreta:

10En el texto de Alberto Díaz, citado al final, aparece como Manuel Mercado. Lo mismo hace Florencio Olivares (Fuente: "El valor del baile Pieles Rojas", Blog Urbanitorium). En la sede social, así como en el estandarte, el nombre que aparece es Damián Mercado.

11 Don Nelson Jeria lo vincula al baile Chuncho (Entrevista realizada el 11 de septiembre, 2014).
En lo sonoro, este "charivari" o Torre de Babel es por demás atrayente y se impone como un caso excepcional en tierra chilena, principalmente porque, a pesar de la diversidad racial, la lengua en uso es la castellana en su totalidad, tanto en las ofrendas, las oraciones, las alocuciones, los discursos como en los corales. Los cantos ('Quele, Quele') en dialecto ritual, de un Aniceto Palza o de un Pablo Donez, quedan refundidos en la chilenidad... (Lavín, 1950, p. 23).

La aparición de este baile Piel Roja suscitó que en las oficinas salitreras se crearan otras danzas. Arturo Barahona menciona bailes originados en las localidades de Negreiros, San Enrique, Peña Chica, Humberstone, etcétera. De los anteriores solo el de Peña Chica sigue existiendo. Pero volvamos al baile de Damián Mercado. La caporala actual, Vicenta Dávila (1942), recrea parte de la historia. Afirma que el baile de Mercado fue en primer lugar un baile danzante, formado por nińos y luego por adultos. Tenía un traje en cuyo pantalón estaba la bandera del Perú. Usaban un sombrero con cintas colgantes y en la punta de ellas ponían caracoles que, al girar la cabeza de los bailarines, sonaban. Luego entraron adultos. A Mercado se le ocurrió formar un baile de pieles rojas, pero siguió conservando sus danzas originales. En la actualidad este baile tiene dos mudanzas, una la de los chunchos y luego la del piel roja. Al preguntarle por qué se llaman pieles rojos, me dice que enojado con Palza, decidió hacer la diferencia con ese nombre.

El año 1941 se produce una reorganización del baile piel roja, según Barahona. Su caporal, el boliviano Pedro Castillo, en 1946 abandona el baile y regresa al país altiplánico. Esto provoca que los diversos bailes se juntaran entre sí y formaran la Sociedad Católica de Pieles Rojas. Algo parecido sucedió en la oficina Mapocho con su caporal Carlos Baltazar, y en Humberstone con Manuel Díaz. El año 1952 en Peña Chica, nace el baile pieles rojas de Peña Chica, y su caporala sería Ana Taucare Hurtado.

En la ciudad aparecen nuevos bailes inspirados en los indios norteamericanos. Los pieles rojas cruzados (1946), los sioux (1953), pieles rojas águilas blancas 
(1956), dakotas (1958). Y los indios cheyennes en 1979. Esta influencia llega a Pedro de Valdivia, Antofagasta, incluso Andacollo.

\section{Chunchos e indios}

La tesis de la imitación esgrimida por el sentido común, en torno al origen de los bailes religiosos como el piel roja y todas sus variantes ya seńaladas, parten del supuesto de que los sujetos reproducen tal cual, una conducta material y simbólica. La imitación sería un acto ingenuo, ya que se supone el hecho de que los actores no poseen la capacidad para crear sus propios modos y su propia ritualidad.

La respuesta de Palza a la folclorista Margot Loyola, citada más arriba, encierra una lógica que es necesario puntualizar. A los sociólogos, por lo general, se nos enseña a desconfiar parcialmente de lo que nos dicen nuestros informantes. $\mathrm{O}$ al menos, a tomar sus declaraciones como algo que hay que ubicar en un contexto más amplio. Al decir de Latour, para los sociólogos críticos, los actores no ven todo el cuadro sino que solo una parte. Hay que enseñarles entonces cuál es el contexto para así ver el todo, el paisaje en su totalidad (Latour, 2005, p. 55). Palza habría actuado motivado por el gusto y el placer que le provocaba ver a los indios norteamericanos en sus rituales. Una conducta casi infantil o irreflexiva. Pero pensar así sería creer que la conducta humana es racional, al modo como Weber la define, es decir con arreglos a fines (2004). El mismo autor habla de las acciones con arreglo a valores y de las así llamadas tradicionales. Latour dice que los informantes hacen las cosas irreflexivamente, mientras que los sociólogos actuamos reflexivamente (Latour 2005, p. 55). El autor citado concluye hablando de las irrelevancias de las preguntas del investigador respecto a las preocupaciones serias de algunos actores (2005, p. 55). Habría que preguntarse qué cara habría puesto el sastre ante la pregunta de la folclorista. Además de la desconfianza en la opinión de Palza, la ciencia moderna desconfía profundamente del sentido común. Este lugar, sobre el que el mundo popular construye sus obras, al decir de Maffesoli, hay que verlo "como una cosa que tiene validez en sí misma, como una manera de ser y de pensar que se basta a sí misma, y que no necesita ningún mundo tras de sí que le dé sentido y respetabilidad" (1977, p. 218). No obstante lo anterior, y como se verá más adelante, ensayamos una interpretación acerca del porqué de este acto creativo. No se desarrolla, por cierto, en un vacío sociocultural, sino que en un contexto al que es necesario recurrir. Grimson nos pone en alerta en tanto es necesario para todo análisis cultural, y sobre todo de formación de identidad, acudir al elemento de la experiencia y de los marcos históricos (2004, p. 191). Una interpretación situada en una tradición hermenéutica, y que en la antropología han sido, entre otros, Turner y Geertz quienes mejor la representan.

Nos inclinamos a pensar, para ofrecer un marco interpretativo al surgimiento de los bailes de indios piel roja, en el modelo de la continuidad y de la ruptura. Esta estrategia cognitiva es presentada por Lalive D'Epinay (1968) cuando elabora su tesis acerca de la aparición del movimiento pentecostal en la sociedad chilena. El sociólogo suizo afirma que para entender el éxito de estas Iglesias en Chile hay que hacerlo desde una doble perspectiva. Por un lado hay un quiebre y por otro, una continuidad. Afirma entonces que el pastor no es más que una continuidad de la figura del hacendado, y la comunidad evangélica una rémora del viejo orden tradicional. Tal perspectiva la utilizo al analizar el auge evangélico en la sociedad aymara del Norte Grande de Chile (Guerrero, 1995). El pastor es la reencarnación del cacique, y el ayllu reaparece en la comunidad de hermanos. Esta estrategia basada en los ejes de la continuidad y de la ruptura ha sido puesta en duda. Señalamos aquí un autor, Nun-Ingerflom, que critica su uso, sobre todo cuando se analiza, en su caso, la Revolución rusa de 1917.

Estamos de acuerdo que en los casos de macrohistoria es complejo establecer relaciones de continuidad y ruptura entre el zarismo y el bolcheviquismo. Ya que como dice el autor, son fenómenos complejos de larga data en el tiempo, que no resisten un análisis de este tipo. Pero en fenómenos locales como el que analizamos geográficamente situado, estas categorías son de utilidad.

Sin embargo, para el caso que nos ocupa, es dable realizarlo, ya que se trata de fenómenos locales, acotados geográficamente, temporalmente delimitados, que bien podrían llamarse micro-culturales. Gadamer apostando por el uso de la hermenéutica, dice: 
"la idea de un nuevo comienzo, de una tabla rasa, no existe" (citado por Nun-Ingerflom, 2006, p. 140).

Recordemos a nivel de hipótesis de interpretación, que la adopción de las mudanzas, trajes y otras consideraciones por parte de los obreros del Norte Grande, no solo puede ser atribuida a la influencia del cine y revistas norteamericanas, sino que también a la existencia previa, en este caso del baile chuncho. Éste posee una estética que ofrece una continuidad con el baile piel roja. Tiene plumas en sus trajes, sobre todo a modo de penacho, usan lanza o chonta. Vienen del mundo de los tobas, vinculado a la cultura amazónica. Ésta es una descripción:

Es un baile tradicional de saltos y gran aparato coreográfico. Los chunchos antiguos usaban turbantes, pollerines, muñequeras y tobilleras de plumas. El chuncho moderno se muestra más desplumado. Las usan solamente en las mangas. En el turbante, que es una especie de morrión adornado con espejos y perlas, llevan plumas paradas. Generalmente visten pantalón blanco y camisa de otro color. Muestra, terciada al pecho, una bandera chilena. Los chunchos dan largos saltos acrobáticos al tiempo que blanden un arco de chonta. Éste lleva un alambre sujeto a las puntas. Al final de una carrera, dan saltos y hacen sonar los arcos como disparos de fusil. Hay algunas compañías mixtas de chunchos y chunchas. Acompañan sus danzas con bandas compuestas de bombo, caja, pitos y flautas y alguna quena (Uribe 1973, p. 91)

En la actualidad, usan bandas de bronces. Ésta es otra descripción que alude a su origen en Bolivia:

Baile mixto de origen boliviano, los bailarines describen círculos, con pasos y saltos largos. Éstos llevan una lanza de madera en la mano denominada "chonta" conectada a un cable tenso que permite percutir con la madera generando un sonido suave característico. Es acompañado con pitos, tambores (bombos) y caja y en los últimos años han sido agregados instrumentos de percusión y bronces. Los vestidos, aunque son de colores uniformes, están ornamentados con plu- mas coloridas y en algunos casos se porta un penacho en la cabeza (Fuente: página web Identidad y Futuro).

Los bailes de indios norteamericanos descritos por el sastre Aniceto Palza, gracias a una entrevista que le realizó Margot Loyola, ${ }^{12}$ tienen estas características y motivaciones:

A la pregunta de por qué la vestimenta de un baile piel roja, Palza responde: "Porque es bonita, porque es distinta y me gustaba. El vestuario de gala era de color café, otro caqui. Las flecuras rojas, guantes blancos, el zapato era reglamentario, tejido con lana de color rojo, negro, amarillo [...] El edecán ${ }^{13}$ del cacique bailaba con un tamborcito y llevaba un tupo en la cabeza, gorrito de piel con dos cachitos".

Sobre las mudanzas, Palza dice: “Toma una lanza que llama "chonta" y me enseñó algunos movimientos. No tiene que achulluncarse la cabeza, ¡bien levantada! Mi cofradía era sencilla y auténtica, nada de hilo de oro [...] no tenía mucha huara, pero sí mucho contenido [...] iiiel estilo era uniforme y militar!!!”

Sobre su turbante, a decir verdad penacho, dice: “Nadie lo tiene, ni lo tendrá! [...] claro que está un poco deteriorado con los ańos, se avejenta uno [...] las plumas son de cóndor, ¿ve? y llegan hasta el suelo [...] nadie podía pisarme la cola [...] Yo era más tieso que gallo 'e pelea y tenía una cara más fea que la del león con hambre”.

Bien puede establecerse, entonces, la relación entre chunchos y pieles rojas. Ambos tienen como común denominador el uso de plumas y de lanzas, aunque sus mudanzas son diferentes. Los chunchos se desplazan en forma horizontal y realizan saltos, ya sea elevando los dos pies o uno solo. Forman grupos de cuatro y producen una coreografía con sus chontas. Este baile en sus coreografías parece representar un pájaro. El baile piel roja se desplaza solo en sentido horizontal. Se agachan, pero no realizan saltos. Ambos son grupos mixtos de hombres y mujeres.

12 La entrevista de Margot Loyola es rica en contenidos. Entrevistó a Palza en el año 1967, en Iquique.

13 Se refiere al hechicero. 
Agreguemos otro elemento para el análisis, en relación al contexto histórico en que surgen estos grupos. Las primeras décadas del siglo XX se caracterizaron, entre otros elementos, por un sostenido y agresivo proceso de "chilenización" por parte del Estado chileno en estas tierras conquistadas, siendo las llamadas Ligas Patrióticas las más violenta en su accionar (González, 2004). El motor de estas campañas fue la "des-peruanización" del Norte Grande, en el caso de Tarapacá. La idea era extirpar todo sustrato andino, léase componentes indios y por tanto bárbaros, de la población. La Iglesia católica chilena realizó una serie de prohibiciones a los bailes, ya que consideraba que las fiestas, y en este caso, la de La Tirana, era un pretexto para fomentar el sentimiento pro peruano (Díaz, 2013, p. 282). Lo mismo sucedía en la fiesta de San Lorenzo. ¿Cómo vivieron los bailes religiosos este proceso?: El caporal del baile de Damián Mercado nos cuenta: “...fue en una época que hubo una crisis en que se cerraron todas las oficinas, pero yo estaba chico, pero lo que le digo me lo contaron. Hubo un despido, pero no sé lo que pasó. Pero lo principal era que mi papá era extranjero, y le dijeron que todos estos extranjeros tenían que irse. Pero no sé por qué pidieron que todos los extranjeros se fueran de la Pampa.
Sí. Cuando mi papá llegó en la noche después del trabajo, en la puerta había una cruz pintada con alquitrán. Entonces mandaron a buscar a mi padre y le dijeron que tenía que irse a su patria. Entonces llegó mi papá y reunió a todos mis hermanos mayores y a mi mamá. Así que decidieron quedarse en Chile y vinieron a Iquique, y así fue como llegamos al Morro.

Desde la lógica de la chilenización es dable pensar que el universo de La Tirana fuese visto como territorio reproductor de lo que se deseaba extirpar. Una posible estrategia de sobrevivencia puede ser advertida, tal vez, en el paso de los indios chunchos a los indios piel roja. Pero como hemos visto, no significa dejar ese pasado de chuncho, sino que se toman algunos elementos y se combinan con la estética del piel roja.

Esta imagen del baile de Damián Mercado, en su sede social de La Tirana, describe lo anterior.

$\mathrm{Su}$ fecha de fundación es elocuente. Es el año 1931. El boom de los wésterns fue en los años cuarenta del siglo XX. La expresión danzantes que aparece en la foto, hay que leerla en el contexto siguiente. Esta cofradía fue en sus inicios, un baile chuncho que poco a poco fue transformándose en pieles rojas.

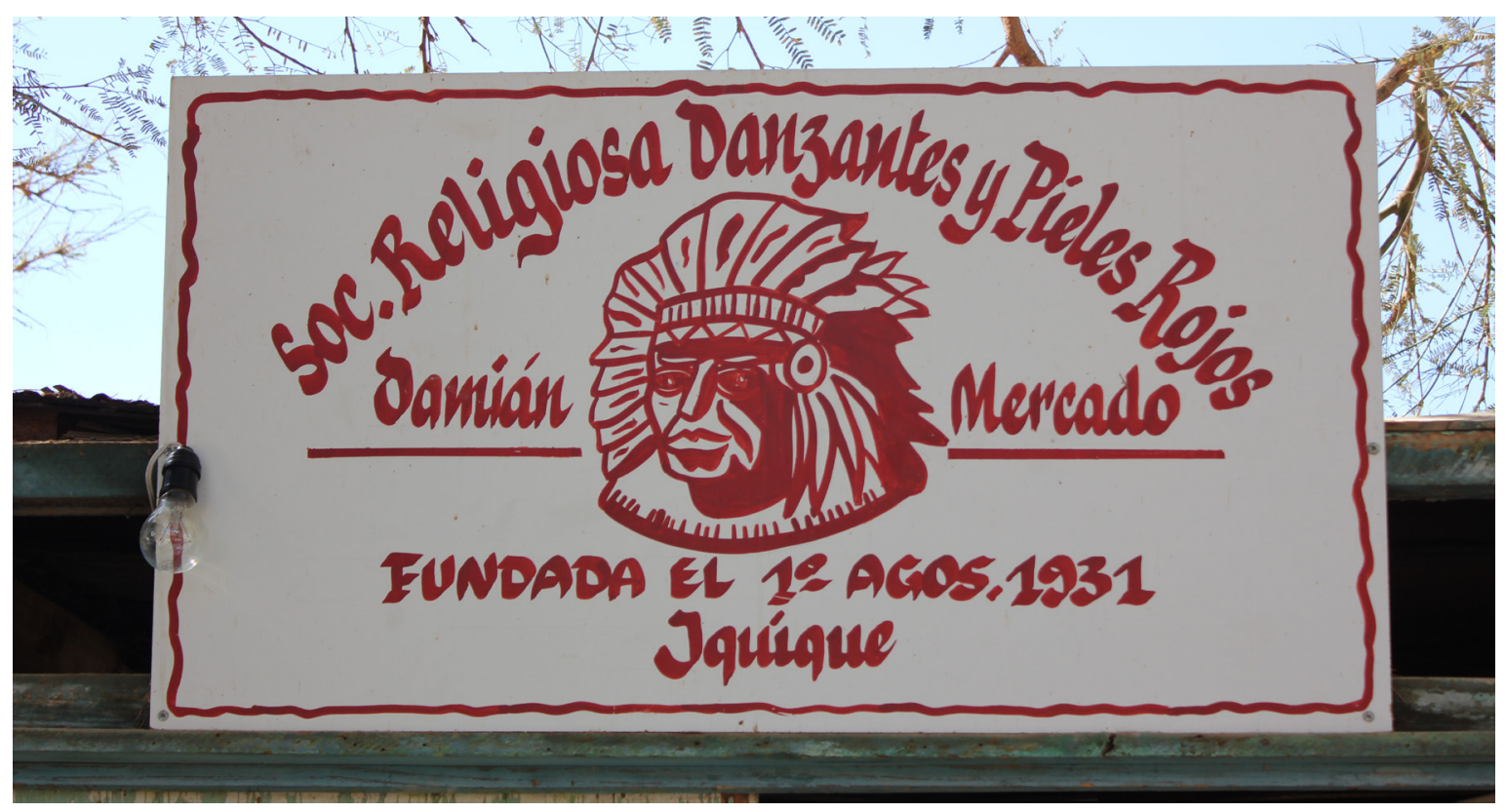

Fotografía 1. Letrero de la Sociedad Religiosa Danzantes y Rojos Damián Mercado. Es probable que este letrero haya sido confeccionado en los años setenta. 
Su fundador Damián Mercado ${ }^{14}$ fue quien hizo la transición de uno al otro. No hay información precisa del año en que esto ocurrió. La tradición oral, en este caso, no es nada de precisa. Como ya se dijo, el baile de Mercado, en la actualidad sigue desarrollando las dos mudanzas, expresando con ello una transición entre el baile chuncho al baile piel roja.

\section{La pluma}

Hemos afirmado más arriba que los bailes religiosos de fines del siglo XIX y comienzos del XX expresaban de modo simbólico la sociedad de su tiempo, o mejor dicho, el mundo que habitaron. Con esta expresión, mundo, queremos enfatizar lo arbitrario y moderno de la separación entre naturaleza y cultura, muchas veces presentada incluso como naturaleza versus cultura. Este habitar fundado en una visión del mundo que Berman denomina "mundo encantado" (1987) encierra la totalidad de una existencia que no se reduce a los hombres y mujeres, sino que alcanza a los animales, las piedras, los árboles, etcétera.

De este mundo complejo pero integrado que bien describen Eliade (1968) y Berman (1987), entre otros, los bailes, en tanto estructura comunitaria, cubrieron sus cuerpos y representaron la otredad (Mercado, 2014). Una identidad fundada en la idea de que el ser humano no es el dueño de la tierra que habita y que debe realizar sistemáticos ritos para mantener el mundo en equilibrio. Estos bailes, como los chunchos o los tobas, por ejemplo, expresan además la amplitud del mundo en que viven. Es uno extenso en el que la selva amazónica aparece vinculada a la pampa del Tamarugal. Lo anterior nos habla de los múltiples intercambios existentes entre diversos pisos ecológicos. Esto habría de alterarse primero con la llegada de los españoles y luego con la Guerra del Pacífico. Hoy es un territorio fragmentado por la existencia de los Estados nacionales.

Bailar es la representación de una identidad que se pone en escena a través del cuerpo. Uno de los elementos más presentes hasta el día de hoy, en aquellos bailes que se insertan en el mundo andino, ${ }^{15}$ es

14 Estuvo en el baile solo dos años, luego enfermó. Está enterrado en el cementerio de Negreiros.

15 Otros como morenos, chinos, gitanos, no usan este elemento de la naturaleza. el uso de plumas. La pluma, en tanto representación de una parte del paisaje andino incluyendo el mundo amazónico, constituye un adorno ritual de primer orden. Trajes cubiertos de este elemento, o bien dispuestos sobre los tobillos, sombreros, etcétera. La pluma es el elemento ritual y decorativo más antiguo que usan los bailes religiosos. Su uso desde la época precolombina era predominante en la élite dirigente. Era una señal de prestigio. Hoy en las fiestas de Norte Grande sigue cumpliendo la misma función estética y ritual. El uso de las plumas al igual que el traje, son un signo de distinción.

Ambos bailes, pieles rojas y chunchos, los usan de un modo evidente. El epígrafe con la que empieza este trabajo así lo indica. El inmenso penacho usado por Aniceto Palza, confeccionado con plumas de cóndor, lo llena de orgullo. Una señal de prestigio, sin duda alguna. ${ }^{16}$

Lo mismo sucede con las chontas y las lanzas. Ambos instrumentos son usados en el contexto del baile de La Tirana, en forma ritual. Acompañan a los danzantes. El paso de la chonta a la lanza, en la perspectiva de la continuidad/discontinuidad, aparece como algo que tiene sentido.

\section{La hoguera}

Hasta los años sesenta, cuando la fiesta de La Tirana aún conservaba su aire local y regional, y se carecía de los servicios básicos, como por ejemplo, la electricidad, los bailes religiosos, sobre todo los que representan a los indios norteamericanos, encendían hogueras y reproducían a su manera, el modo de vida de estos indios.

Este rito tenía dos funciones: abrigarse del frío y reproducir el complejo ritual que se le asociaba a los indios de las estepas norteamericanas. La noche pampina helada alcanzaba con las hogueras cierta calidez. En toda la plaza y en los alrededores del pueblo, se alzaba el fuego. Los hechiceros, los mediadores con las fuerzas sagradas, casi tan impor-

16 Nelson Jeria dice que Palza usaba un penacho que le llegaba hasta el suelo. Y entraba solo a la iglesia y le cantaba a la Virgen. Su mujer agrega: "Parecía un verdadero indio" (Entrevista realizada el 11 de septiembre, 2014). 
tantes como el caporal, pero dependiendo de éste, ejecutaban sus mudanzas saltando incluso sobre el fuego. Se dice que don Arturo Barahona, antes de ser el dueño y caporal, era un excelente hechicero. Sus danzas frente al fuego son recordadas por los viejos bailarines.

La rica pampa del Tamarugal, la misma que abasteció de leña a la minería de plata de Huantajaya y luego a la empresa del salitre, suministraba la leña y el carbón para encender las decenas de hogueras que los bailes de indios precisaban para reproducir el ritual del fuego. Se escribe sobre esta ceremonia:

El número central de su presentación constituye su danza del fuego, que se ejecuta durante la noche del día 15 de julio, en la fiesta en honor de la Virgen del Carmen de La Tirana. Saltan sobre las llamas de grandes fogatas, que encienden con ramas de chamiza. ${ }^{17}$ Como ceremonia complementaria a la danza misma, el brujo de la cofradía hace fumar la pipa de la paz a los bailarines novicios, mientras transcurre la presentación coreográfica (Fuente: https://es.wikisource.org/wiki/ Enciclopedia_Chilena/Folclore/Pieles_Rojas,_Baile_de).

La danza al fuego o como quiera que se le llame se inserta en lo que Eliade (1968) denomina cristianismo cosmológico, aludiendo a los elementos que están presentes en la naturaleza y a los que se brinda cuidado y respeto, por lo mismo que es básico para la alimentación y el cuidado del frío. Los aymaras, en su elaborada cosmovisión, le rinden culto al agua, a través de la Pachamama (Van Kessel, 1980).

Para la oficialidad de la Iglesia católica la performance de los pieles rojas no era de su agrado. Como tampoco lo es en la actualidad la manda (Guerrero y Guizardi, 2012). Pero sobre los peregrinos individuales no ejercen mucho control, más que la sanción ética.

17 Hierba silvestre y medicinal de la familia de las gramíneas, que nace en tierras frescas y aguanosas. Sirve para techumbre de chozas y casas rústicas.
La danza al fuego era la memoria y el archivo que se representaba, y recordaba la presencia india en el continente. Lo étnico y popular, tan bien conjugados en las fiestas religiosas del Norte Grande, fueron dispositivos que desafiaban constantemente el monopolio de acceso a lo sagrado que tenía la Iglesia. Por lo mismo, la figura del caporal y del hechicero, en el caso de los indios, era vista con sospecha y desconfianza por la Iglesia y con admiración por los peregrinos.

Una de las formas que halló el Estado para terminar con estas ceremonias fue a través de la dotación de bienes básicos de los que el poblado carecía. Indirectamente, logró el objetivo que la Iglesia católica buscaba. Al iluminar con energía eléctrica la plaza y el pueblo, no hubo necesidad de encender hogueras. Toda vez que con el aumento de los bailes religiosos, hubo que maximizar el uso del espacio para que todos pudieran danzar. El siguiente cuadro nos sirve para resumir ambos bailes:

\begin{tabular}{|c|c|c|}
\hline Categoría & Baile chuncho & Baile pieles rojas \\
\hline $\begin{array}{l}\text { Fecha de } \\
\text { fundación }\end{array}$ & 1931 & 1938 \\
\hline Performance & $\begin{array}{l}\text { Indios } \\
\text { amazónicos }\end{array}$ & $\begin{array}{l}\text { Indios } \\
\text { norteamericanos }\end{array}$ \\
\hline $\begin{array}{l}\text { Vestimenta y } \\
\text { elementos }\end{array}$ & Pluma/Chonta & $\begin{array}{l}\text { Pluma/Lanza y } \\
\text { hachas de chonta } \\
\text { y cuchillo de } \\
\text { madera }\end{array}$ \\
\hline Música & Percusión/viento & Percusión/Bronce \\
\hline Ritmo & $2 / 3$ & $3 / 3$ \\
\hline Baile & $\begin{array}{l}\text { Tradicional de } \\
\text { saltos }\end{array}$ & Modernos \\
\hline Fila & $\begin{array}{l}2 \text { / Hombre - } \\
\text { Mujer }\end{array}$ & $\begin{array}{l}\text { 2/ Hombre - } \\
\text { Mujer }\end{array}$ \\
\hline
\end{tabular}




\section{Conclusiones}

Como hemos afirmado a lo largo de estas páginas, más allá de la tesis de la imitación, postulamos la idea de la continuidad y la ruptura para explicar el paso del baile chuncho al piel roja. Paso que además tiene que ver con un contexto de "chilenización" en el que el conjunto étnico andino era visto con sospecha. De allí la necesidad de reinventar, sin abandonar la danza ni el canto.

Las fiestas del Norte Grande de Chile están marcadas por una fuerte disposición a la innovación en las formas del cantar y del bailar. Sobre estos dos sustentos a lo largo de más de un siglo, hemos asistido a procesos de apropiaciones de las más diversas índoles. Uno de ellos, quizás el que más llama la atención, es la presencia de bailes de indios norteamericanos.

Los bailes religiosos del Norte Grande poseen una inventiva que, apoyada sobre la tradición, va siendo renovada poco a poco. El uso de instrumentos de bronce que casi todos los bailes emplean y que data de la década del cincuenta, es uno de ellos. Las adaptaciones de canciones populares a ritmos nortinos, es también muestra de lo anterior.

Estos tipos de bailes se estructuraron en torno a un líder carismático y a menudo autoritario. Un dirigente que además era el dueño del baile. Este tipo de liderazgo, muy común en el mundo popular, logra, aparte de crear nuevas estructuras, generar por diversas razones, cismas y fragmentaciones. La historia de los pieles rojas y de otros bailes en el Norte Grande parece seguir esa tendencia.

Hay por cierto un acto creativo en base a los elementos que la sociedad pone a su disposición. A fines del siglo XIX es lo local, regional y andino aquello que suministra los modelos a seguir, en los trajes y mudanzas. Desde los años cuarenta y hasta la actualidad, es el cine norteamericano estilo wéstern. La traducción cultural opera en base a sujetos, como el mismo Palza y sus recreaciones.

\section{Referencias citadas}

Bravo-Elizondo, P. (1986). Cultura y teatro obreros en Chile. 1900-1930. Madrid: Ediciones Michay.

Campos, L. et al. (2009). Cuyacas: Música, danza y cultura en una sociedad religiosa en la fiesta de La Tirana. Santiago: Fondart, Consejo Nacional de la Cultura y las Artes / Universidad Academia de Humanismo Cristiano.

Díaz, A. (2013). Al compás de un danzar telúrico. Pampinos e indígenas en la fiesta de la virgen de la Tirana (1900-1950). En González, S. (Comp.). La sociedad del salitre. Protagonistas, migraciones, cultura urbana y espacios públicos (pp. 279-300). Santiago: RIL Editores.

Durkheim, E. (1982). Las formas elementales de la vida religiosa. El sistema totémico en Australia. Madrid: Akal.

Eliade, M. (1968). El mito del eterno retorno. Buenos Aires: Emecé.

Fernández, M. D. C. (2009). James Fenimore Cooper y los nativos de Norteamérica. En Del Pino-Díaz, R., Riviale, P. y Villarías-Robles, J. (Eds.). Entre textos e imágenes. Representaciones antropológicas de la América Indigena (pp. 227-238). Madrid: Gobierno de España, Ministerio de Ciencia e Innovación, CSIC.

García, P. (2009). Fiesta de La Tirana en el contexto del Centenario de 1910: Mito y consolidación temprana de su origen y prestigio. Revista de Ciencias Sociales, 23, 2357. Universidad Arturo Prat, Iquique.

Garrido, P. (1944). La Tirana (1944). Documental. 16 minutos. Armando Rojas Castro y Pablo Garrido (Dirs.). Alfonso Reyes Messa (guion). Servicio Cinematográfico de la Dirección General de Información y Cultura (DIC), Santiago.

González, S. (2004). El dios cautivo. Las Ligas Patrióticas en la chilenización compulsiva de Tarapacá (1910-1922). Santiago: LOM.

Grimson, A. (Comp.). (2004). La experiencia argentina y sus fantasmas. En La cultura en las crisis latinoamericanas (pp. 177-194). Buenos Aires: Clasco Libros.

Guerrero, B. (1994). A Dios Rogando... los pentecostales en la sociedad aymara del Norte Grande de Chile. Ámsterdam: Free University Press. 
Guerrero, B. (2010). Arturo Godoy. Iquique: Ediciones El Jote Errante / Gobierno Regional de Tarapacá.

Guerrero, B. (2014). La Tirana: el ańo en que la fiesta estuvo en peligro. Revista Diálogo Andino, 45, 181-192. Universidad de Tarapacá (Diciembre), Arica.

Guerrero, B. y Guizardi, M. (2012). Sacralidades en conflicto: las mandas en la fiesta de La Tirana. Revista de Estudos da Religião (Brasil), 6(22), 99-136.

Hobsbawm, E. (2013). El "Vaquero" de Estados Unidos: ¿Un mito internacional. En Un tiempo de ruptura. Sociedad y cultura en el siglo XX, capítulo 22 (pp. 269-285). Barcelona: Planeta.

Innerarity, D. (2008). Ética de la hospitalidad. Barcelona: Ediciones Península.

Joas, H. (1998). El pragmatismo y la teoría de la sociedad. Madrid: Centro de Investigaciones Sociológicas.

Lalive, C. (1968). El refugio de las masas. Santiago: Editorial del Pacífico.

Latour, B. (2005). Reensamblar lo social. Una introducción a la teoría del actor-red. Buenos Aires: Manantial.

Lavín, C. (1950). La Tirana. Fiesta ritual del norte de Chile. En Colección Ensayos, 8, 3-27. Instituto de Investigaciones Musicales, Facultad de Ciencias y Artes Musicales, Universidad de Chile.

Maffesoli, M. (1997). Elogio de la razón sensible. Una visión intuitiva del mundo contemporáneo. Buenos Aires: Paidós Studio.

Méndez, P. (2016). Los Pieles Rojas del Desierto de Atacama. Historia, músicas y danzas de Promeseros a la Virgen del Carmen en La Tirana (1930-2016). Tesis para optar al grado de magíster en Artes con mención en Musicología. Facultad de Artes, Escuela de Posgrado, Universidad de Chile, Santiago. URL: http://repositorio.uchile.cl/handle/2250/138532

Mercado Guerra, J. (2014). Práctica ritual y tensiones identitarias en las danzas promesantes de la fiesta del santuario de ayquina, norte de Chile. Diálogo Andino [online] 45, 193-213 [visitado 21.05.2016]. <http://www.scielo.cl/scielo.php?script=sci_ arttext\&pid=S0719-26812014000300016\&lng=es\&nrm =iso $>$. ISSN 0719-2681. http://dx.doi.org/10.4067/S071926812014000300016.

Morris, B. (1987). El reencantamiento del mundo. Santiago: Cuatro Vientos.

Nun-Ingerflom, C. S. (2006). Cómo pensar los cambios sin las categorías de ruptura y continuidad. Un enfoque hermenéutico de la revolución de 1917 a la luz de la historia de los conceptos. Revista Res Publica. Revista de Historia de las Ideas Políticas, 16, 129-152. Universidad Complutense de Madrid, Madrid.

Prado, A. (2012). Los teatros del desierto. Producción del espacio durante el ciclo salitrero, Chile. 1830-1979. Tesis presentada para obtener el grado de doctor en la Universidad Politécnica de Catalunya (ETSAB), Barcelona.

Serfaty, P. (2003). L'appropiation. En Segaud, M. et Brun, J. (Dirs.). Dictionnaire critique de l'habitat du logement (pp. 27-30). Paris: Editions Armand Colin.

Tennekes, H. y Koster, P. (1986). Iglesia y peregrinos en el norte de Chile: Reajustes en el balance de poderes. Cuaderno de Investigación Social, 18, 57-86. Centro de Investigación de la Realidad del Norte, Iquique.

Uribe Echeverría, J. (1973). Fiesta de La Tirana de Tarapacá. Valparaíso: Ediciones Universitarias de Valparaíso.

Van Kessel, J. (1987). Lucero del Desierto. Iquique: Universidad Libre de Ámsterdam y CEREN.

Vansina, J. (1977). La tradición oral. Barcelona: Labor.

Vera-Pinto, I. (2016). Historia Social del Teatro en Iquique y la Pampa 1900-2015. CORE Tarapacá, FNDR. Cultura, Iquique.

Weber, M. (2003). Economía y Sociedad. México: Fondo de Cultura Económica.

\section{Prensa consultada}

El Tarapacá. "Con gran éxito y con asistencia de un público numerosísimo se desarrollan las fiestas de la Tirana” (17 de julio, 1937, p. 4). 


\section{Fuentes electrónicas}

http://identidadyfuturo.cl/2012/07/historia-y-bailes-de-lafiesta-de-la-tirana/ consultado el 4 de junio, 2014.

http://es.wikisource.org/wiki/Enciclopedia_Chilena/Folclore/Pieles_Rojas,_Baile_de, el 17 de septiembre, 2014.

htpp:/urbatorium.blogspot.com/2011/10/el-valor-de-losbailes-PielesRojas-en.html.U 4wlTuKSo. 